\section{ÁGUAS DE PERTENCIMENTO: UM ESTUDO SOBRE PERCEPÇÃO E PRÁTICA DE EDUCAÇÃO AMBIENTAL}

\author{
WATERS OF BELOGING: A STUDY ON \\ PERCEPTION AND PRACTICE OF EN- \\ VIRONMENTAL EDUCATION
}

\author{
Maria Ivanilde Meneses \\ Rejane Santos Oliveira
}

\section{Resumo}

Esse artigo versa sobre a importância do estudo da percepção ambiental para efetiva prática da Educação Ambiental. O objetivo principal da pesquisa foi analisar a percepção que os alunos têm em relação ao problema da poluição dos rios e da constante falta de água no município de São Cristóvão. Trata-se de uma pesquisa qualitativa através da observação participante e interpretação dos desenhos produzidos pelas crianças com base em categorias relacionadas à percepção ambiental. Através da análise dos mapas mentais produzidos pelos alunos, evidenciou-se que a percepção ambiental pode ser utilizada como valiosa ferramenta para a educação ambiental, especialmente no contexto escolar, pois, possibilita compreender melhor as inter-relações existentes entre os seres humanos e o ambiente, bem como, conhecer de que forma os alunos percebem o ambiente no qual estão inseridos e principalmente, sensibiliza-los para as questões socioambientais, permitindo-lhes a aquisição de uma consciência ecológica e os tornando aptos a exercer a plena cidadania, buscando soluções para os problemas ambientais detectados em seu entorno.

Palavras-chave: Educação Ambiental. Percepção Ambiental. Mapas Mentais.

\begin{abstract}
This paper deals with the importance of the study of environmental perception for the effective practice of Environmental Education. The main objective of the research was to analyse student's perception regarding the problem of river pollution and the constant lack of water at São Cristóvão City. This is a qualitative research through participant observation and interpretation of the drawings produced by children based on categories related to environmental perception. Through the analysis of the mental maps produced by the students, it was shown that environmental perception can be used as a valuable tool for environmental education, especially in the school context, because it allows a better understanding of the interrelationships existing between humans and the environment, as well as to know how the students perceive the environment in which they are inserted and, above all, to sensitise them to the socio-environmental issues, enabling them to acquire an ecological conscience and making them able to exercise full citizenship, seeking solutions for the environmental problems detected in their environment.
\end{abstract}

Keywords: Environmental Education. Environmental Perception, Mental maps. 


\section{Introdução}

Na sociedade contemporânea, torna-se cada vez mais indispensável atitudes de cuidados com o ambiente, tendo em o esgotamento dos recursos naturais do planeta. Neste contexto emergem os estudos em práticas educativas que visem à sensibilização dos sujeitos para que estes se sintam pertencentes ao ambiente

Nesse âmbito, o grande desafio da escola é favorecer o desenvolvimento da educação ambiental de forma interativa e criativa. Sobre isso, Layrargues (2004) argumenta que a Educação Ambiental em uma perspectiva transformadora, aponta a educação como sendo um processo contínuo e global no qual, todos agem e refletem sobre suas práticas, visando à transformação da realidade vivida e principalmente, buscando novas estratégias para o enfrentamento dos problemas socioambientais de modo democrático e sustentável. Desse modo, o professor deve cooperar para que os alunos desenvolvam a percepção e o cuidado com o ambiente.

A partir destes pressupostos, a pesquisa aborda a percepção ambiental de uma turma de alunos do $2^{\circ}$ ano da Escola Estadual Professor Manoel dos Passos de Oliveira Teles situada no município de São Cristóvão, estado de Sergipe. Conforme Moreira (2004), a pesquisa em percepção ambiental engloba o entendimento que as pessoas possuem em relação ao lugar onde vivem e com o seu dia a dia afeta a conduta que o indivíduo assume no meio ambiente, sendo uma ferramenta instauradora da sensibilização para conservação desse meio. Os principais objetivos foram: favorecer a identificação dos problemas ambientais da comunidade e favorecer a mudança de comportamento dos alunos em prol do correto descarte de resíduos, uso racional da água e conservação do meio ambiente.

A abordagem predominante da pesquisa foi qualitativa através da observação participante e posterior análise dos desenhos produzidos pelos alunos utilizando-se de categorias relacionadas à percepção ambiental. De acordo com, Goldenberg (2004), através da observação participante, o pesquisador tem a possibilidade de coletar dados em meio à sua atuação na vida em coletividade, mantendo-se atento às pessoas para analisar como as mesmas agem, dialogando para desvendar os significados de tudo que analisou, podendo confrontar e considerar as soluções dadas em diferentes circunstâncias.

\section{Percepção ambiental apartir do processo educativo}

A percepção é a maneira pela qual o ser humano observa o meio ambiente e de que modo interpreta as leis que o regem, segundo seus conhecimentos, vivências, crenças, sentimentos, culturas e ações (ARAÚJO, 2010).

Tuan (1980, p.4) alega que a percepção "é tanto a resposta dos sentidos aos estímulos externos, como a atividade proposital na qual certos fenômenos são claramente registrados enquanto outros são bloqueados". Articula ainda que, o homem é um animal visual. Em outras palavras, dependente mais da visão que dos outros sentidos para sentir conscientemente o mundo que o cerca. De acordo com Del Rio (1996), compreende-se a percepção como sendo:

[...] um processo mental de interação do indivíduo com o meio ambiente que se dá através de mecanismos perceptivos propriamente ditos e principalmente, cognitivos. Os primeiros são dirigidos pelos estímulos externos, captados através dos cincos sentidos [...]. Os segundos são aqueles que compreendem a contribuição da inteligência, admitindo-se que a mente não funciona apenas a partir dos sentidos e nem recebe essas sensações passivamente [...] (DEL RIO, 1996, p.03).

Dessa forma, Tuan e Del Rio defendem que a mente compõe e exprime a realidade apreendida por meio de esquemas perceptivos e imagens mentais, com atributos específicos (PROFES, 2006).

Essa condição deve-se a uma série de razões e um claro exemplo disso, refere-se ao fato de que um mesmo ambiente pode ter diferentes valores e interpretações para as pessoas.

Ao se referir à percepção ambiental, Fernandes (2004) também enfatiza a importância dos sentidos e reconhece que a percepção ambiental pode ser compreendida como o resultado da reação dos sentidos em relação ao meio no qual o indivíduo 
encontra-se inserido, permitindo o seu raciocínio, o estabelecimento de valores, pensamentos, reações e interações positivas ou negativas sobre o meio ambiente. Com base nessa percepção, o ser humano relaciona-se com o mundo, induz seus pares, interfere no ambiente, segue na direção do conhecimento e do exercício da cidadania ambiental.

Segundo Tuan (1980), a percepção dos indivíduos sofre uma série de influências que a modificam. Tais influências são estabelecidas como influências pessoais, culturais e físicas. As influências pessoais são determinadas por características pessoais, tais como espécie, instrução, vivência do indivíduo no meio. Já as influências culturais estão diretamente relacionadas à conjuntura na qual os indivíduos são criados e que, podem possibilitar diversificadas formas de vislumbrar o mundo. Por último, ocorrem as influências físicas em que, a percepção ambiental também se sujeita ao cenário que está sendo percebido.

Nesse âmbito, nota-se que, ao longo de sua trajetória, o homem tenta alterar o seu meio, objetivando suprir suas necessidades. Entretanto, algumas dessas modificações e influências afetam drasticamente a qualidade de vida de muitas gerações.

Do ponto de vista de Silva (2002), a percepção ambiental inclui o desenvolvimento da cognição ambiental, demonstrando a maneira como o indivíduo visualiza o meio ambiente e como assimila as leis que o conduzem, em decorrência de experiências, conhecimentos, crenças, emoções, culturas e atitudes. Tal percepção simboliza um ambiente ideal para aprimorar o conhecimento, atitudes, valores e características favoráveis ao meio, dispondo da educação ambiental como um instrumento essencial para interagir nesse processo.

Evidencia-se que, assim como ocorre com os ambientes construídos, o ambiente natural é percebido segundo os princípios e conhecimentos individuais em que são conferidos valores e significância num determinado nível de importância em suas vidas.

Partindo dessa premissa, torna-se imprescindível que a sociedade contemporânea se interesse cada vez mais pelas questões ambientais, revendo comportamentos, reduzindo as agressões praticadas contra a natureza e principalmente, utilizando os recursos naturais de modo racional para que esses, não venham a faltar num breve espaço de tempo.

Neste sentido, o estudo da percepção ambiental é de suma importância para que possamos compreender as inter-relações existentes entre o homem e o meio ambiente, como também aprender a protegê-lo e cuidá-lo da melhor forma, além de fazer com que os indivíduos percebam o ambiente em que vivem podendo, desta forma, ajudar no desenvolvimento de metodologias para despertar nas pessoas a tomada de consciência frente aos problemas ambientais (ARAÚJO, 2010, p. 56).

Desta forma, os estudos de percepção ambiental podem subsidiar a Educação Ambiental na constante luta em defesa do meio natural, auxiliar na consolidação de uma relação harmoniosa entre os seres humanos e a natureza, permitindo a tomada de ações responsáveis em relação ao meio ambiente e a existência de um futuro com maior qualidade de vida para todos. De acordo com Faggionato (2002)

Diversas são as formas de se estudar a percepção ambiental: questionários, mapas mentais ou contorno, representação fotográfica, assim como trabalhos em percepção ambiental que buscam não apenas o entendimento do que o indivíduo percebe, mas que busque promover a sensibilização, bem como o desenvolvimento da percepção e compreensão do ambiente (FAGGIONATO, 2002, p.).

Dentre os meios de estudo da percepção ambiental, destacam-se os mapas mentais que, são caracterizados por serem ilustrações que uma pessoa faz e conduz em seu sistema cognitivo, resultante da experiência vivenciada num determinado local ou das informações que dele obtenha (ARAÚJO, 2010).

No que concerne a esse método, Maroti (2004) alega que:

O uso de mapas mentais ou afetivos tem sido considerado uma metodologia adequada às pesquisas socioambientais com comunidades de indivíduos com pouca ou nenhuma escolaridade, principalmen- 
te pela riqueza de informações simbólicas que podem proporcionar. Eles são utilizados para a representação gráfica dos elementos físicos, biológicos e antrópicos presentes em uma determinada área da paisagem com base na experiência do indivíduo (MAROTI, 2004, p. 188).

Ressalta-se que o desenvolvimento do mapa mental em meio ao ensino sistematizado, se propõe a avaliar o nível da consciência espacial dos discentes. Em outras palavras, compreender de que forma os alunos percebem o lugar em que vivem. "Neste sentido, através de mapas mentais, torna-se possível reconhecer os valores desenvolvidos previamente pelos alunos, bem como avaliar a imagem que eles trazem do seu ambiente (ARAÚJO, 2010, p. 58)".

Ainda no que diz respeito aos mapas mentais, Tuan (1980) adota duas concepções para o termo. Na primeira, mapas mentais são "como representações cartográficas de como ambientes estão avaliados por pessoas diferentes" (TUAN, 1980, p.209). Em sua segunda concepção, são "como mapas traçados a mão que as pessoas desenham ou esboços de ruas urbanas e continentes". Resumidamente, "um mapa mental pode ser a planta de ruas que uma pessoa recorda ao descrever o caminho para um amigo", bem como, pode ser "a representação cartográfica de um geógrafo sobre as atitudes que as pessoas têm de determinados lugares" (TUAN, 1980, p.209).

Na perspectiva de Seemann (2003), "mapas na percepção ambiental não devem ser vistos como produtos cartográficos, mas como formas de comunicar, interpretar e imaginar conhecimentos ambientais" (SEEMANN, 2003, p.7).

Seemann (2003) também destaca que:

Além da sua natureza de representar a realidade sem ser a mesma realidade e de servir como metáfora, o mapa também possui outra característica: um alto potencial imaginário. $\mathrm{O}$ mapa precisa ser compreendido além do seu rigor científico. Frequentemente, o mapa é apenas julgado pela sua precisão e sua verossimilhança sem deixar margem para a imaginação humana (SEEMANN, 2003, p.8).

A partir destas considerações, buscou-se utilizar a percepção como ferramenta para a prática em Educação Ambiental para que os educandos percebessem os problemas ambientais de sua comunidade, suas causas e adotassem novas posturas de modo a minimizar os impactos decorrentes da degradação.

\section{Percepção e Educação Ambiental}

Em meio ao avanço do sistema capitalista, fortemente marcado pelo crescimento exacerbado da produção e o exagerado consumo de produtos que não são essenciais à nossa subsistência, constata-se a violenta degradação e esgotamento dos recursos naturais, em decorrência de uma maior necessidade de matérias-primas para a produção de bens de consumo. Essa situação tem agravado consideravelmente, os problemas ambientais já existentes (BOLIGIAN, 2005; SANTOS, 2011).

Nesse momento, objetivando a redução das ações humanas prejudiciais ao meio ambiente e o desenvolvimento de uma sociedade crítica e capaz de manter uma relação sustentável entre homem e natureza, revela-se o valor da educação ambiental.

De acordo com a Lei n. ${ }^{\circ} 9.795$ que, institui a Política Nacional de Educação Ambiental:

Entende-se por Educação Ambiental os processos por meio dos quais o indivíduo e a coletividade constroem valores sociais, conhecimentos, habilidades, atitudes e competências voltadas para a conservação do meio ambiente, bem de uso comum do povo, essencial à sadia qualidade de vida e sua sustentabilidade (BRASIL, 1999).

De acordo com Santos:

Educação Ambiental é a tomada de ações em prol do meio ambiente visando à utilização dos seus recursos de modo a preservá-lo para as futuras gerações. Para garantir o envolvimento dos indivíduos com esses princípios, faz-se necessário 
um trabalho que leve as pessoas a desenvolverem a capacidade de cogitar sua realidade questionando-as, levando-as a pensar sobre as relações presentes entre o homem e o meio ambiente (SANTOS, 2011, p. 23).

Assim, agir em proveito do meio ambiente é uma tarefa árdua que, requer a adoção de atitudes assertivas em prol do uso racional dos recursos naturais e melhoria da qualidade de vida de todos. Nesse sentido, torna-se indispensável o desenvolvimento de atividades de Educação Ambiental, principalmente no ambiente escolar, com o intuito de propagar informações e orientações que possibilitem aos cidadãos tornarem-se cada vez mais conscientes de suas ações frente às questões ambientais.

Como detentora de um conteúdo emancipatório, a Educação Ambiental permite a quebra de paradigmas, possibilitando alterações das ações humanas, vinculadas ao fazer educativo e principalmente, favorecendo mudanças comportamentais individuais e coletivas, locais e globais, econômicas e culturais (LEFF, 2001; LOUREIRO, 2004; SANTOS, 2011). Por esse motivo, a Educação Ambiental:

[...] deve oportunizar uma mudança rápida do indivíduo em um mundo em evolução. Ela deve ser permanente, geral, expressiva e responsável em preparar o indivíduo para analisar de modo crítico os atuais problemas do planeta e propor ações que visem à sua superação. Ao mesmo tempo, deve proporcionar conhecimentos adequados à necessidade de desempenhar uma função produtiva $\mathrm{e}$ em proteção ao meio ambiente, sempre caminhando com valores éticos (SANTOS, 2011, p. 24).

Somado a isso, a educação ambiental tem por propósito a sensibilização das pessoas acerca dos problemas presentes no ambiente, procurando transformá-las em seres críticos que participem ativamente das deliberações sobre seus futuros, exercitando dessa maneira o direito à cidadania, elemento indispensável no processo de "sustentabilidade socioambiental” (SANTOS 2011).

\section{A escola e a Educação Ambiental}

O espaço escolar se constitui em um espaço propício para o cultivo dos valores e do cuidado com o outro e com o ambiente. Enquanto formativo, "a escola é um local, dentre outros (família, trabalho, clube, igreja, etc.), onde não só os alunos, como também os professores, exercem sua cidadania, ou seja, comportam-se em relação a seus direitos e deveres" (PENTEADO, 2007, p. 94).

Nesse contexto, no que concerne às atribuições da escola frente à Educação Ambiental, Tristão (2008) afirma que:

O papel da escola é construir valores e estratégias que possibilitem aos/às estudantes determinarem o que é melhor conservar em sua herança cultural, natural e econômica para se alcançar um nível de sustentabilidade na comunidade local que contribui, ao mesmo tempo, com os objetivos em escala nacional e global (TRISTÃO, 2008, p. 66).

Torna-se extremamente necessário que, a escola como parte integrante da sociedade, fomente discussões acerca das relações homem-ambiente e, para isso, precisa investir em formação docente para que, o professor esteja apto a desenvolver um trabalho crítico e reflexivo em Educação Ambiental (TRISTÃO, 2008).

Sob tal perspectiva, a Educação Ambiental centraliza suas atenções para a formação de cidadãos ambientalmente comprometidos, estejam eles em idade escolar ou não. Portanto, esses indivíduos necessitam ser devidamente preparados para melhor agir no contexto social, tornando-se aptos a reivindicar maior prudência, responsabilidade e participação nas decisões socioambientais (SANTOS, 2011).

No tocante a educação formal, a escola se constitui em um espaço favorável para formação através do desenvolvimento de práticas educativas que formem cidadãos com uma nova postura ética em relação ao cuidado com o ambiente. Neste sentido:

A escola é, sem sombra de dúvida, o local ideal para se promover esse processo. As disciplinas escolares são os recursos didáticos através dos quais os conhecimentos científicos de que uma sociedade 
já dispõe são colocados ao alcance dos alunos. As aulas são o espaço ideal de trabalho com os conhecimentos e onde se desencadeiam experiências e vivências formadoras de consciências mais vigorosas porque alimentadas no saber (PENTEADO, 2007, p.16).

Ainda no que tange a escola, essa é tida por Santos (2011) como:

[...] o espaço existente na sociedade que serve para discutir questões, possibilitar o desenvolvimento do pensamento crítico, trazer informações, contextualizar e dar nova direção para que o aluno busque mais conhecimento. (SANTOS, 2011, p. 40).

Diante da necessidade de formação de cidadãos críticos e conscientes acerca da conservação do ambiente, manutenção dos recursos naturais e para que haja a verdadeira inserção da Educação Ambiental na escola, é necessária a efetiva participação do educador ambiental que, por meio da formação adequada, estará devidamente capacitado a atuar de maneira interdisciplinar junto ao alunado (SANTOS, 2011).

Sobre as características do docente que trabalha com Educação Ambiental, Santos (2011) defende que:

O educador ambiental na escola necessita, assim como o aluno, apreciar e valorizar o trabalho que está se propondo a realizar. Esse professor deve se especializar mediante leituras na área, participando de encontros, adquirindo um conhecimento sólido para trabalhar de modo pertinente os conteúdos da área e com metodologias adequadas para o desenvolvimento do conhecimento e de atitudes críticas sobre a realidade socioambiental (SANTOS, 2011, p. 41).

Nesse contexto, o profissional de educação que busca constantemente seu aperfeiçoamento, passa a deter um leque de possibilidades, tornando-se capaz de desenvolver práticas pedagógicas eficazes não somente no ambiente de sala de aula, mas também, na comunidade escolar e até mesmo na comunidade entorno da escola (SANTOS, 2011).

O professor que atua com Educação Ambiental deve permitir aos seus alunos o despertar crítico, a conquista da autoconfiança, o desenvolvimento da cidadania e inseri-los nas atuais discussões sobre o meio ambiente (PESTANA, 2007; SANTOS, 2011).

Em complemento à ação do educador ambiental e ainda no que se refere à necessidade de mudanças no trabalho escolar, Penteado (2007) é categórica ao destacar que:

[...] é preciso dar um passo transformador. Esse passo aponta na direção de se orientar os trabalhos escolares por uma lógica ambiental, a fim de que passemos da escola informativa para a escola formativa. É preciso e possível contribuir para a formação de pessoas, capazes de criar e ampliar espaços de participação das "tomadas de decisões" de nossos problemas socioambientais (PENTEADO, 2007, p. 56).

\section{Práticas realizadas com os alunos}

A Escola Estadual Professor Manoel dos Passos de Oliveira Teles foi criada e denominada pelo Decreto Estadual $\mathrm{n}^{\circ}$ 5.672, datado de 08 de fevereiro de 1983, para oferecer o ensino fundamental e fica situada na Av. Dom José Vicente Távora, s/n, no município de São Cristóvão, estado de Sergipe. Dispõe de uma estrutura física composta por cinco salas de aula, uma biblioteca, uma secretaria, uma diretoria, uma cozinha, três banheiros masculinos, três banheiros femininos, um banheiro para portadores de necessidades especiais e um laboratório de informática. A estrutura administrativa da escola é mantida pela rede pública estadual. Conta com Direção, Secretário, Coordenação e Conselho Escolar, um corpo docente constituído por treze professores de alta competência e o corpo discente formado por duzentos e quarenta e sete alunos matriculados e distribuídos nos turnos matutino e vespertino, entre turmas de $1 .^{\circ}$ ao $5^{\circ}$ ano do Ensino Fundamental.

Após aprovação e efetiva liberação dos alunos pela da equipe diretiva e coordenação pedagógica da instituição de ensino, foi utilizada a técnica de observação direta intensiva durante a realização de uma visita de campo ao Rio Paramopama para que os alunos tivessem a oportunidade de 
conhecer a real situação desse curso d'água que, encontra-se poluído por uma série de dejetos descartados inadequadamente pelas comunidades circunvizinhas.

Nessa oportunidade, dos 22 alunos que compõem a turma do $2^{\circ}$ ano "B", do turno vespertino, apenas 17 crianças compareceram à referida visita.

Dentre as práticas metodológicas utilizadas, optou-se pelo desenho em virtude de o texto verbal trazer consigo um maior grau de dificuldade para exprimir pensamentos e/ou emoções e, o texto não verbal (desenho) encontrar-se fortemente presente na rotina das crianças.

Ao tratar dos desenhos e rabiscos produzidos pelas crianças, Derdyk (2004) afirma que:

A criança rabisca pelo prazer de rabiscar, de gesticular, de se aprimorar. O grafismo que daí surge é essencialmente motor, orgânico, biológico, rítmico. Quando o lápis escorrega pelo papel, as linhas surgem. Quando a mão para as linhas não acontece. Aparecem, desaparecem. A permanência da linha no papel se investe de magia e esta estimula sensorialmente a vontade de prolongar este prazer (DERDYK, 2004, p.56)

Complementando essa afirmação, Sans (2007, p. 42) destaca que ao desenhar, a criança "prende-se pouco à aparência do momento e introduz os mistérios sentidos pelo objeto focalizado e o ambiente que o rodeia. Assim, coloca todo o seu sentimento pessoal que, no momento, domina seu interior". Em seus desenhos, a criança manifesta sentimentos verdadeiros, expressando-se de maneira consciente e inconsciente.

Em meio aos traços e cores, a criança grava suas percepções, sua visão de mundo e manifesta como se encontra inclusa num determinado ambiente (SANS, 2007).

A partir das observações realizadas "in loco" e já de volta ao ambiente de sala de aula, foi solicitado aos alunos que elaborassem individualmente desenhos abordando os aspectos que mais lhe chamaram atenção durante a visita ao rio. Em seguida, os alunos apresentaram seus desenhos aos demais colegas e explicaram suas percepções em relação ao meio ambiente visitado, com o in- tuito de fomentar uma discussão entre as crianças sobre tudo o que foi visualizado no decorrer da visita.

\section{Resultados e discussão}

Para o efetivo alcance dos objetivos traçados na pesquisa foram analisados dezessete mapas mentais produzidos pelos alunos do $2^{\circ}$ ano $\mathrm{B}$, turma existente na escola no turno vespertino.

Inicialmente, a análise desses mapas mentais partiu da identificação dos elementos captados por meio dos desenhos e num segundo momento, realizou-se sua subdivisão em duas categorias: (1) Desenhos contendo elementos naturais do ambiente biótico e abiótico; (2) Desenhos que apresentavam elementos construídos ou transformados pelo homem, conforme indicados nas Tabelas 1 e 2, em consonância com as disposições estabelecidas nos PCN - Meio Ambiente (1997).

Conforme expresso nos Parâmetros Curriculares Nacionais - Meio Ambiente (1997), os elementos podem ser classificados em: (1) elementos naturais do meio ambiente e (2) elementos manipulados pelos seres humanos.

Cabe frisar que, de fato, não há uma natureza inalterada pelos seres humanos, tendo em vista que a espécie humana se configura como parte integrante da vida no planeta, a partir do momento em que vem povoando e relacionando-se com os mais variados ecossistemas há milhões de anos (BRASIL, 1997).

Reforçando essa afirmação, observa-se por meio do desenho 01 que, ao registrar suas percepções em relação ao ambiente observado durante a visita ao Rio Paramopama, a aluna representou em elementos naturais intactos a exemplo do céu, sol e nuvens que foram detectados em meio às intervenções humanas presentes na paisagem visitada. 
Desenho 01: Elementos naturais intactos presentes na paisagem
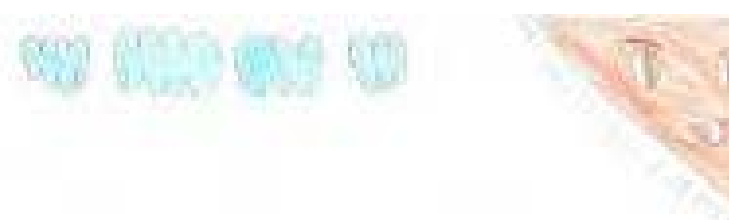

Fonte: Aluna do $2^{\circ}$ ano do ensino fundamental.

Do outro lado, conceituam-se como sendo elementos produzidos ou modificados pela ação humana (artificiais), os elementos também denominados de construídos do meio ambiente. Nesse grupo estão inclusos:

[...] desde matérias primas processadas, até objetos de uso, construções ou cultivos. Em determinados sistemas prevalecem os elementos adaptados pela sociedade humana, como cidades e áreas industriais, praias urbanizadas, plantações, pastos, jardins, praças e bosques plantados etc. (PCN, 1997, p. 235).

As tabelas exibidas a seguir sinalizam o número de desenhos em quem elementos foram registrados pelas crianças, levando-se em consideração a categorização acima mencionada.
Tabela 01: Elementos naturais encontrados nos mapas mentais selecionados.

\begin{tabular}{|c|c|c|}
\hline Categoria 1 & Elementos & Frequência \\
\hline \multirow{8}{*}{$\begin{array}{l}\text { Elementos } \\
\text { naturais }\end{array}$} & Sol & 08 \\
\hline & Nuvem & 06 \\
\hline & Céu & 06 \\
\hline & Pessoas & 12 \\
\hline & Animais & 06 \\
\hline & Árvores & 03 \\
\hline & Grama/ vegetação & 04 \\
\hline & Rio & 17 \\
\hline
\end{tabular}

Fonte: Oliveira, 2016

Levando-se em conta a esquematização dos elementos naturais e artificiais, constata-se que nos mapas mentais elaborados, os alunos deram maior ênfase aos elementos naturais. Nota-se que, esse resultado se aproxima da categorização de meio ambiente que Reigota (2010) faz com base em estudos desenvolvidos com a percepção ambiental.

De acordo com Garrido (2014), durante sua análise, Reigota determina como sendo uma das classificações em percepções sobre o meio ambiente a classificação naturalista que, possui como principal característica o fato dos sujeitos conceberem meio ambiente como sinônimo de natureza, "com predominância de elementos naturais, tais como os elementos bióticos e abióticos" (GARRIDO, 2014, p.678).

Como pode ser observado na Tabela 1 , dentre os elementos naturais evidenciados nos mapas, o rio esteve presente em todos os 17 desenhos produzidos pelas crianças.

A seguir, através dos desenhos 02 e 03, são apresentados alguns dos mapas mentais nos quais o rio poluído foi considerado como elemento de maior destaque no cenário observado. 
Desenho 02: Rio poluído em destaque.

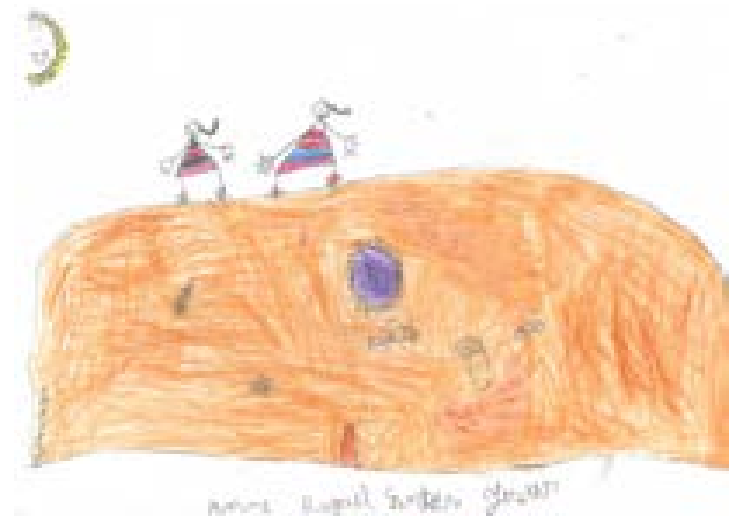

Fonte: Aluna do $2^{\circ}$ ano do ensino fundamental.

Desenho 03: Destaque para sujidade da água.

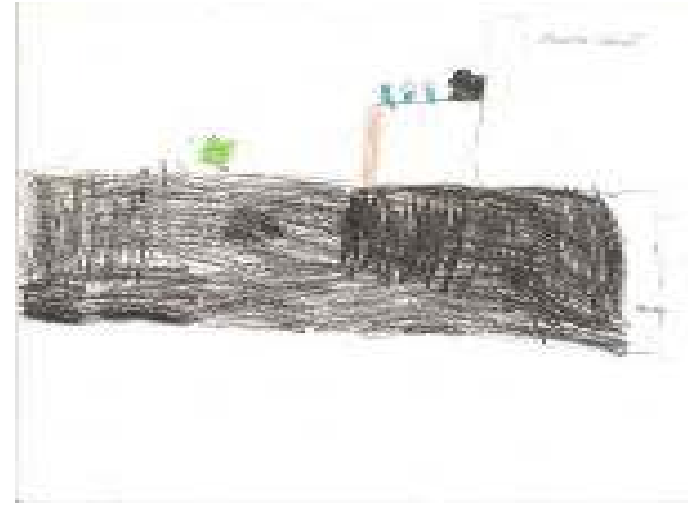

Fonte: Aluna do $2^{\circ}$ ano do ensino fundamental.

Outro dado que merece destaque diz respeito à presença de pessoas. Em 12 dos 17 desenhos, as crianças representaram o ser humano como elemento integrante do meio ambiente e principal causador da degradação evidenciada no local visitado. Além disso, assim como pode ser visualizado nos desenhos 04 e 05, entre os 12 mapas em que são retratadas pessoas, 7 demonstram a presença dos alunos inclusos no ambiente visitado.
Desenho 04: Alunos como integrantes do ambiente.

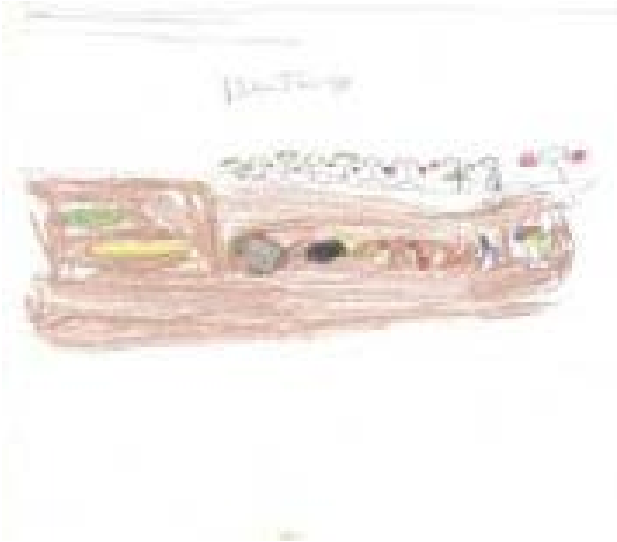

Fonte: Aluna do $2^{\circ}$ ano do ensino fundamental.

Desenho 05: Alunos inclusos na paisagem.
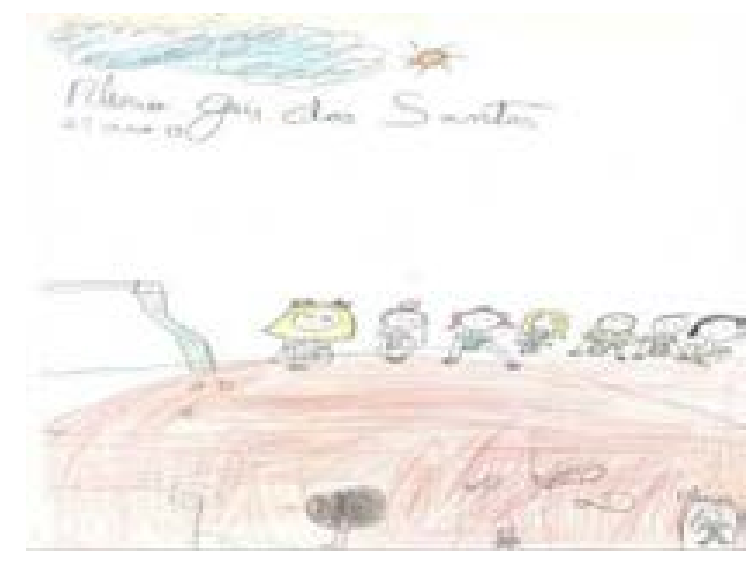

Fonte: Aluna do $2^{\circ}$ ano do ensino fundamental.

Segundo Archela; Gratão e Trostdorf (2004), os mapas mentais são imagens espaciais que os indivíduos possuem de lugares conhecidos, de forma direta ou indireta. Tais imagens que, de acordo com os autores, podem ser de um espaço pertencente ao cotidiano, de localidades distantes, ou até mesmo, constituídas a partir de eventos sociais, culturais e econômicos, revelados nos meios de comunicação, organizam-se por um processo que correlaciona percepções próprias diretamente ligadas aos sentidos humanos, aspectos conscientes e inconscientes, associados à fase de desenvolvimento mental do indivíduo, sua herança biológica, cultural e educação.

Ainda acerca dos elementos naturais, 06 alunos incluíram em seus mapas mentais, animais típicos do rio, a exemplo do peixe e do caranguejo, como demonstrado nos desenhos 06 e 07. 
Desenho 06: Presença de peixes no rio.

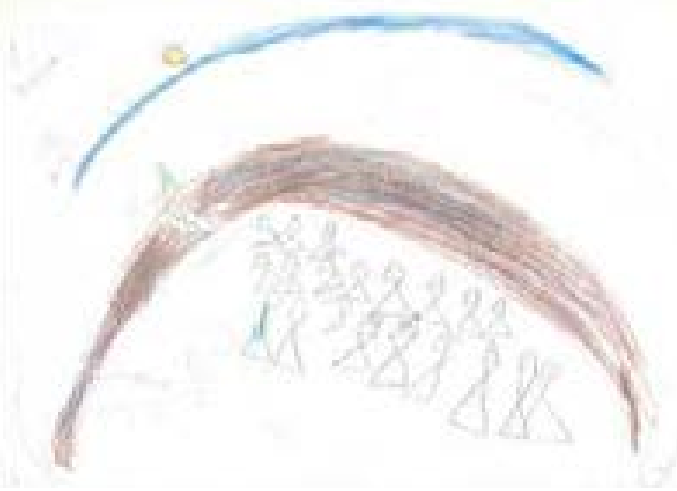

Fonte: Aluna do $2^{\circ}$ ano do ensino fundamental.

Desenho 07: Visualização de peixe e caranguejo.

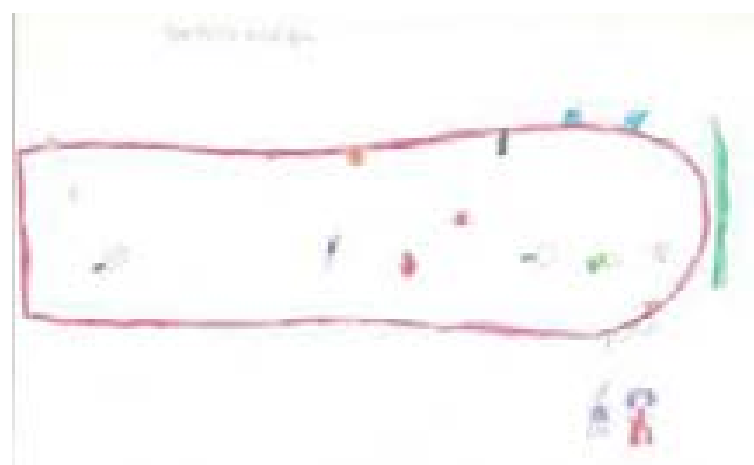

Fonte: Aluna do $2^{\circ}$ ano do ensino fundamental.

Tabela 02: Elementos artificiais encontrados nos mapas mentais selecionados.

\begin{tabular}{|c|l|c|}
\hline Categoria 2 & Elementos & Frequência \\
\hline ELEMEN- & Ponte & 07 \\
\cline { 2 - 3 } TOS ARTIFI- & $\begin{array}{l}\text { Tubulação de } \\
\text { esgoto }\end{array}$ & 02 \\
\cline { 2 - 3 } & Lixo/ poluição & 17 \\
\hline
\end{tabular}

Fonte: Oliveira, 2016.

No que tange aos elementos artificiais, como pode ser visualizado através da Tabela 2, aspectos relativos à poluição e a presença de lixo foram evidenciados nos 17 mapas mentais analisados. Evidencia-se por meio dos desenhos 08 e 09 que, alguns alunos registraram os resíduos e outros elementos visualizados nas águas do rio durante a visita "in loco": ventilador, sacolas plásticas, pente, pedaços de armário de cozinha, frasco de shampoo, tonel, dentre outros.
Desenho 08: Registro de ventilador nas águas do rio.

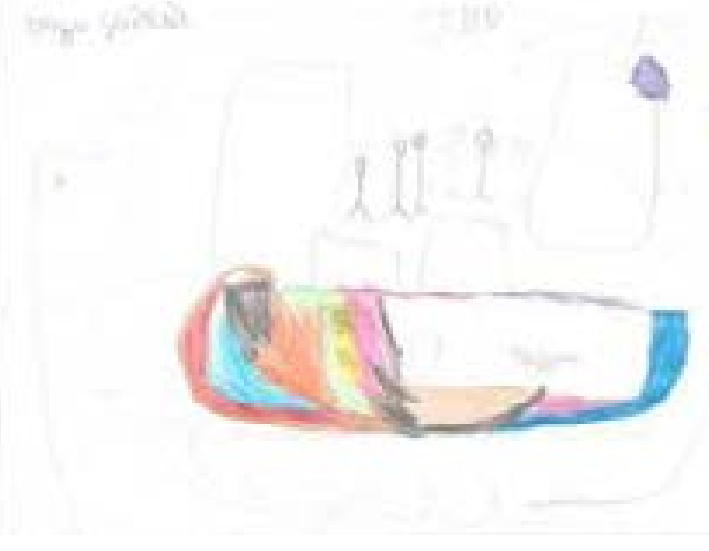

Fonte: Aluno do $2^{\circ}$ ano do ensino fundamental.

Desenho 09: Identificação de vários resíduos.

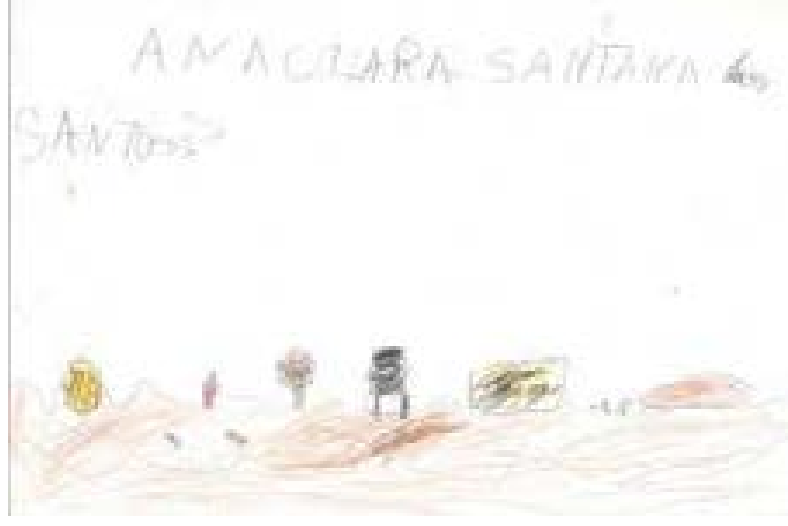

Fonte: Aluna do $2^{\circ}$ ano do ensino fundamental.

Outro dado importante se refere aos elementos relacionados à água (ponte) que se encontra presente em 07 dos mapas produzidos. Isso mostra que, por conhecerem a realidade do local, conseguem representa-la graficamente com uma maior riqueza de detalhes.

Através dos desenhos 10 e 11 pode-se visualizar o registro de elementos modificados pela ação humana, a exemplo da ponte onde os alunos permaneceram durante a visita ao rio. 
Desenho 10: Detalhamento do ambiente.

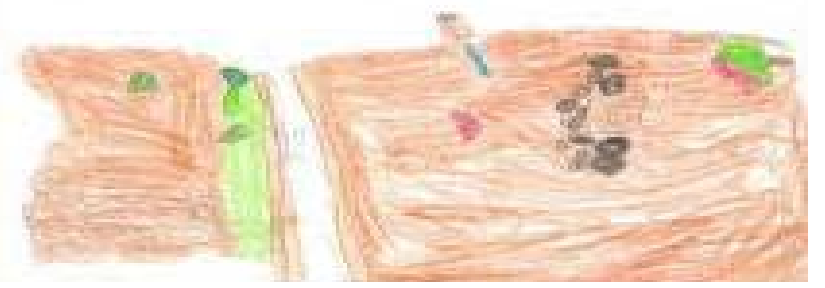

Fonte: Aluna do $2^{\circ}$ ano do ensino fundamental.

Desenho 11: Identificação da ponte.

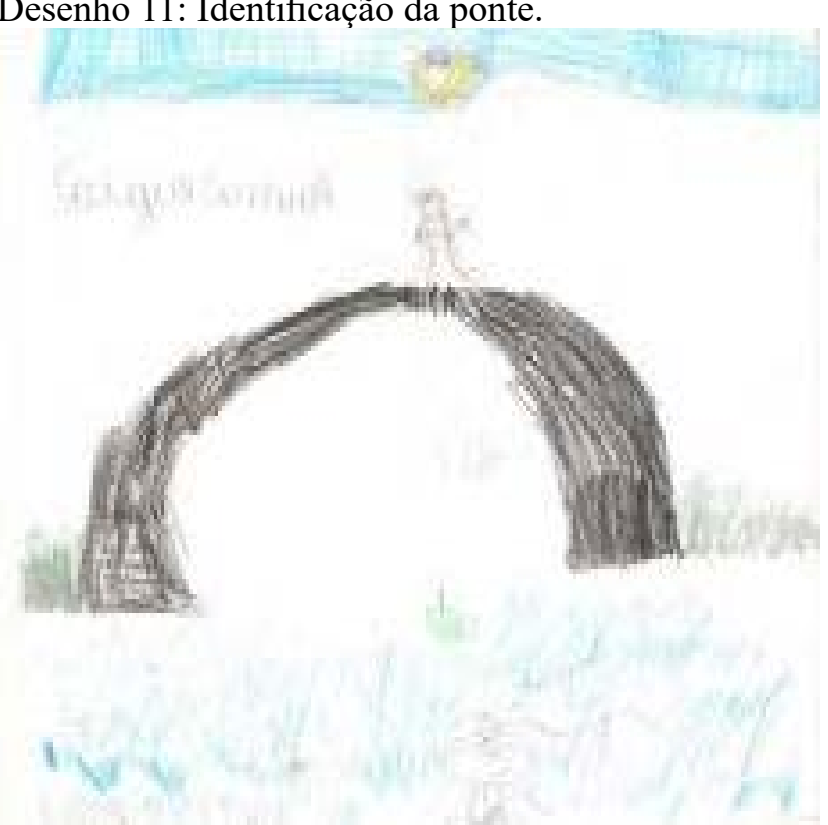

Fonte: Aluno do $2^{\circ}$ ano do ensino fundamental.

Além disso, em 04 mapas mentais, os alunos desenharam um ambiente afetado em decorrência da ação humana, porém, sem a presença do ser humano, como pode ser constatado nos desenhos 12 e 13, identificados a seguir.
Desenho 12: Rio repleto de resíduos.

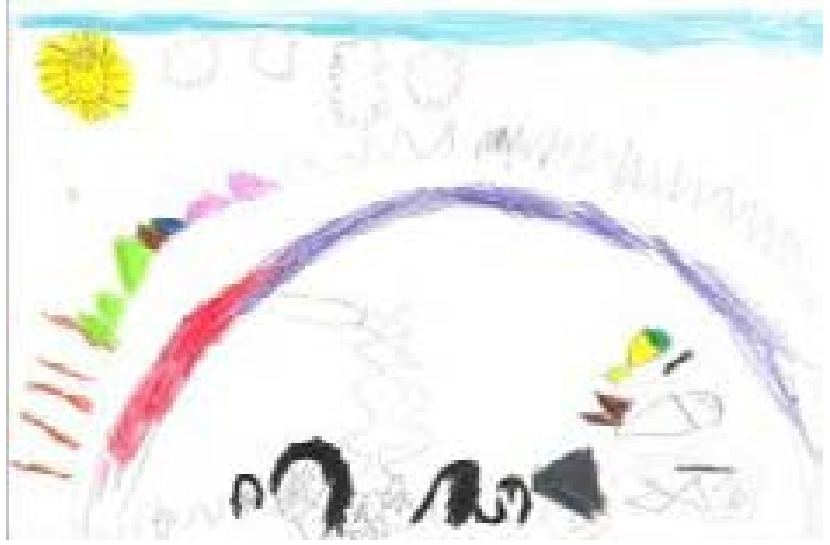

Fonte: Aluna do $2^{\circ}$ ano do ensino fundamental.

Desenho 13: Ausência de seres humanos.

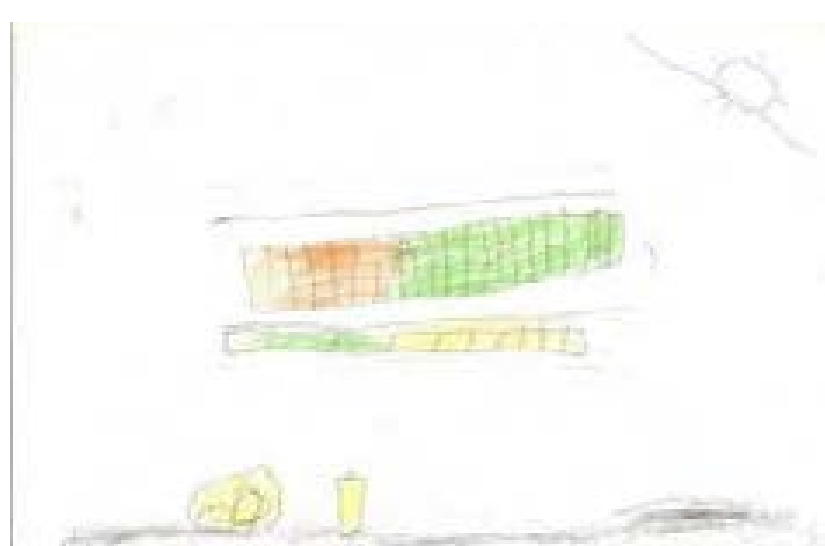

Fonte: Aluno do $2^{\circ}$ ano do ensino fundamental.

Reforçando a importância do desenho, Ferreira \& Silva (2001) argumentam que:

As impressões que as crianças têm da realidade experienciada não se amontoam, imóveis, em seu cérebro. Elas constituem processos móveis e transformadores, que possibilitam à criança agrupar os elementos que ela mesma selecionou e modificou e combiná-los pela imaginação. $\mathrm{O}$ desenho que a criança desenvolve no contexto da escola é um produto de sua atividade mental e reflete sua cultura e seu desenvolvimento intelectual (Ferreira \& Silva, 2001, p. 56).

\section{Considerações finais}

Por meio da visita ao Rio Paramopama, os alunos tiveram a oportunidade de visualizar num ambiente real, um dos problemas socioambientais que afetam o município de São Cristóvão/SE. A partir desse momento, os mesmos foram questio- 
nados acerca de suas impressões e suas respostas ao longo do processo, deram indícios sobre o que foi compreendido e no que ainda é necessário reforçar o conteúdo.

No momento em que se depararam com a poluição presente na região do rio, as crianças visualizaram o quanto as pessoas podem fazer mal a natureza e, que esse tipo de atitude traz malefícios a toda a população do município.

Evidenciou-se que após realização da visita com alunos ao Rio Paramopama, ocorreu uma significativa mudança de comportamento das crianças com relação ao descarte dos resíduos produzidos em local apropriado e ao uso consciente da água. Ao falar sobre a importância de se economizar a água durante as atividades rotineiras, as crianças compartilharam de suas experiências junto às famílias. Também se reforçou a necessidade de conservar esse bem, não o poluindo e o utilizando de maneira racional.

Mediante o enfrentamento de problemas socioambientais, pretendeu-se intervir de maneira positiva na realidade vivenciada, objetivando mudanças significativas no modo de agir dos alunos frente aos elementos que os cercam, fazendo com que os mesmos, compreendessem a importância de se conservar o meio ambiente, realizando o descarte dos resíduos sólidos em local apropriado, como também, utilizando a água, que já se apresenta como um bem de uso restrito no município de São Cristóvão, de maneira responsável.

A guisa de conclusão, através da análise dos mapas mentais produzidos pelos alunos, evidenciou-se que a percepção ambiental pode ser utilizada como valiosa ferramenta para a educação ambiental, especialmente no contexto escolar, pois, possibilita compreender melhor as inter-relações existentes entre os seres humanos e o ambiente, bem como, conhecer de que forma os alunos percebem o ambiente no qual estão inseridos e principalmente, sensibiliza-los para as questões socioambientais, permitindo-lhes a aquisição de uma consciência ecológica e os tornando aptos a exercer a plena cidadania, buscando soluções para os problemas ambientais detectados em seu entorno.

\section{Referências bibliográficas}

ARAÚJO, M. I. O. Educação Ambiental: o construto de práticas pedagógicas públicas/ organização, Maria Inez Oliveira Araújo, Maria José Nascimento Soares - Aracaju: Criação, 2010.

ARCHELA, R. S.; GRATÃO, L. H. B.; TROSTDORF, M. A. S. O lugar dos mapas mentais na representação do lugar. In: Geografia, Londrina, v. 13, n. 1, jan./jun. 2004. Disponível em: <http:// www.uel.br> Acesso em: 15 jun. 2016.

BOLIGIAN, L. et al. Geografia: espaço e vivência. In: Consumo, meio ambiente e desigualdade no espaço mundial. 2. ed. São Paulo: Atual, 2005.

BRASIL. Lei no 9.795, de 27 de abril de 1999. Disponível em < http://www.planalto.gov.br/ccivil_03/leis/L9795.htm>. Acesso em: 25 de jul. 2016 .

BRASIL. Secretaria de Educação Fundamental. Parâmetros Curriculares Nacionais: Meio Ambiente e Saúde / Secretaria de Educação Fundamental. Brasília: [s.n.], 1997.

DEL RIO, V. e OLIVEIRA, L. de. (org.) Percepção Ambiental: a experiência brasileira. São Paulo: Studio Nobel; Universidade Federal de São Carlos, 1996.

DERDYK, E. Formas de pensar o desenho: desenvolvimento do grafismo infantil. São Paulo: Scipione, 2004.

DIAS, G. F. Educação Ambiental: princípios e prática. 3 ed. São Paulo: Gaia, 1994.

FAGGIONATO, S. Percepção ambiental. Texto disponibilizado em 2002. Disponível em: $<$ http:// educar.sc.usp.br/biologia/textos/m_a_txt4. html>. Acesso em: 26 de jul. 2016.

FERNANDES, R. S. et al. O uso da percepção ambiental como instrumento de gestão em aplicações ligadas às áreas educacional, social e ambiental. In: ENCONTRO DA ANPPAS, 2. 2004, Indaiatuba. Anais... Belém: Associação Nacional de Pós-Graduação e Pesquisa em Ambiente e Sociedade, 2004.

FERREIRA, S.; SILVA, S.M.C. "Faz o chão pra ela não ficar voando": o desenho na sala de 
aula", In S. Ferreira (org.). O ensino das Artes: construindo caminhos. $3^{\mathrm{a}} \mathrm{Ed}$. Porto Alegre: Papirus, 2001.

GARRIDO, L. S.; MEIRELLES, R. M. S. Percepção sobre meio ambiente por alunos das séries iniciais do Ensino Fundamental: considerações à luz de Marx e de Paulo Freire. In: Ciênc. Educ., Bauru, v. 20, n. 3, p. 671-685, 2014.

GOLDENBERG, M. A arte de pesquisar: como fazer pesquisa qualitativa em Ciências Sociais. 8 . ed. - Rio de Janeiro: Record, 2004.

LAYRARGUES, P. P. (coord.). Identidades da educação ambiental brasileira. Brasília: Ministério do Meio Ambiente, 2004.

LEFF, E. Saber ambiental: sustentabilidade, racionalidade, complexidade, poder. 7. ed. Tradução de Lúcia Mathilde Endlich Orth. Petrópolis: Vozes, 2001.

LOUREIRO, C. F. B. Trajetória e fundamentos da Educação Ambiental: por uma Educação Ambiental Transformadora. São Paulo: Cortez, 2004.

MACEDO, R. L. G., Percepção e Conscientização Ambiental. Minas Gerais: Editora UFLA/ FAEPE, 2000.

MAROTI, P. S. A percepção ambiental de antigos trabalhadores da fazenda Jatahy (região de Ribeirão Preto - atual estação ecológica de Jataí): mudanças topofílicas ao longo do tempo provocadas por diferentes ciclos econômicos. In: OLAM - Ciência \& Tecnologia Rio Claro/SP, Brasil Vol. 4 No 1 Pag. 189 Abril / 2004.

MOREIRA, D. A. O método fenomenológico na pesquisa. São Paulo: Pioneira Thomson Learning, 2004.

PEDRINI, A; COSTA, E.A; GHILARDI, N. Percepção Ambiental de Crianças e Pré-Adolescentes em Vulnerabilidade Social para Projetos de Educação Ambiental. Revista Ciência e Educação, v.16, n.1, p.163-179, 2010.

PENTEADO, Heloísa Dupas. Meio Ambiente e formação de professores. 6 . ed. São Paulo: Cortez, 2007.

PESTANA, A. P. S. Educação ambiental e a escola, uma ferramenta na gestão de resíduos sólidos urbanos. Disponível em $<$ http://www.cenedcursos.com.br>. Acesso em 17 jul.2016.

PROFES, M. B. Contribuições da percepção ambiental a intervenções mais sustentáveis em Assentamentos precários em áreas de vulnerabilidade ambiental: caso Ilha Grande dos Marinheiros/ Marcos Berwanger Profes. - 2006.

REIGOTA, M. Meio Ambiente e Representação Social. 8. ed. São Paulo: Cortez, 2010.

SANS, P. T. C. Pedagogia do Desenho Infantil. Campinas, Alínea, 2007.

SANTOS, F. A. S.; PARDO, M. B. L. Educação ambiental: um caminho possível. Porto Alegre: Redes Editora, 2011.

SEEMANN, J. Mapas e Percepção Ambiental: do Mental ao Material e vice-versa. Vol. $3, n^{\circ} 1, p$. 200-223, setembro de 2003. Rio Claro.

SILVA, M. M. P. da. Meio Ambiente na visão de Educadores do Sertão Paraibano. In Anais IV Simpósio Brasileiro de Etnobiologia e Etnoecologia. Recife, 2002.

TRISTÃO, M. A educação ambiental na formação de professores. 2. Ed. São Paulo: Annablume; Vitória: Fapitec, 2008.

TUAN, Y. F. Topofilia - Um estudo da Percepção, Atitudes e Valores do Meio Ambiente. Ed. Difel: São Paulo, 1980.

VESENTINI, J. W.; VLACH, V. Geografia crítica. São Paulo: Ática, 2004.

\section{Sobre os autores}

Rejane Santos Oliveira: Licenciada em Pedagogia e Especialista em Educação Ambiental com Ênfase em Espaços Educadores Sustentáveis pela Universidade Federal de Sergipe. Professora da Rede Pública Estadual de Ensino de Sergipe. E-mail: rejanes_oliveira@hotmail.com

Maria Ivanilde Meneses: Mestra em Educação, Especialista em Educação Ambiental para professores e em Coordenação Pedagógica, licenciada em Pedagogia pela Universidade Federal de Sergipe. Professora na Rede Pública Municipal 
de Ensino de Aracaju. E-mail: menesesivanilde@ msn.com 